\title{
Editorial
}

\section{Sustainable Tourism Marketing}

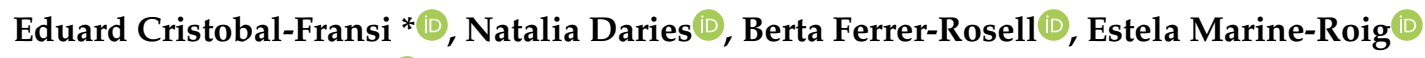 \\ and Eva Martin-Fuentes (i)
}

Department of Business Management, University of Lleida, 25001 Lleida, Catalonia, Spain; ndaries@aegern.udl.cat (N.D.); berta.ferrer@aegern.udl.cat (B.F.-R.); estela.marine@udl.cat (E.M.-R.); eva@aegern.udl.cat (E.M.-F.)

* Correspondence: ecristobal@aegern.udl.cat; Tel.: +34-97-370-3253

Received: 18 February 2020; Accepted: 25 February 2020; Published: 2 March 2020 updates

\begin{abstract}
In this article, we introduce the themes and approaches covered in this special issue on Sustainable Tourism Marketing. Its objective has been to analyze the main contributions made as a result of research related to sustainable tourism-marketing management and current trends in this field. This issue has gathered articles about the marketing of destinations and the marketing and communication management of companies and tourism organizations from a sustainable tourism perspective. This editorial piece provides a useful introduction to the relationship between tourism and sustainable marketing management that can be used by researchers and practitioners to develop tourism marketing strategies from a sustainable perspective.
\end{abstract}

Keywords: sustainable tourism; tourism marketing; destination management; destination marketing organization; tourist behavior

\section{Introduction}

Due to the great importance and influence of tourism in society, public institutions and companies have proposed to emphasize the positive impacts of tourism and reduce its negative impacts at the economic, social, and environmental levels [1]. Therefore, it is necessary to reach a balance between sustainability and tourism development of the destination. The sustainability of the tourist destination has become, in fact, a key element of differentiation to increase its competitiveness [2].

For the tourism industry, the environment and its conservation are vital aspects. Initiatives and proposals have emerged aimed at implementing a new concept related to tourism, called 'sustainable tourism'. This concept has been defined by the UNWTO [3] as 'Tourism that takes full account of its current and future economic, social and environmental impacts, addressing the needs of visitors, the industry, the environment and host communities' (p. 12). Tourist activity is inseparable from the surrounding environment; thereby, it necessary to raise awareness among tourists, residents, and managers of tourist establishments of making the tourism industry sustainable by adopting sustainable practices [4]. To do this, marketing management is essential.

Initially, it may seem that the concepts of marketing and sustainability are incompatible [5]. Marketing, in general, and advertising, in particular, have been criticized for spreading fraudulent messages in the promotion of sustainable products or services, personified in the practice of 'green washing', which involves deceiving consumers about a company's environmental performance in order to make a commercial profit [6,7]. However, marketing is essential for businesses and sustainable tourist destinations. Good marketing management is responsible for the numbers and types of tourists who visit a destination and for guaranteeing viable destinations that provide valuable contributions to economic development and growth [8]. While the roles of public administration and tourism businesses are key in the design and development of sustainable destinations, marketing has an 
important function in determining how successfully destinations achieve their goals and objectives, in both the short and medium term [9].

\section{Structure and Contents of the Thematic Issue}

The aim of this special issue is to add new and diverse knowledge to the existing body of literature on the relationship between marketing and sustainability in the specific field of tourism. All of the articles take different perspectives. Ten articles in the special issue, written by accredited researchers from various countries, present original studies that explore the implications of applying sustainable practices to tourism marketing.

The first of the articles is titled 'Visiting intangible cultural heritage tourism sites: From value cognition to attitude and intention', and is written by Qiu et al. The authors took TFTLC (the traditional firing technology of Longquan celadon) as a study case, investigating residents' value cognition and emotional attitudes in regard to a heritage site and nearby city in Zhejiang Province, China, and analyzing the formation path of tourism intention. Their research clarifies how intangible cultural heritage (ICH) tourism products can promote the sustainability of ICH in environmental, economic, and social aspects, and the authors confirm the potential to predict tourists' motivations and intentions by studying their value cognition and emotions, thus providing valuable insight into product development, marketing, and post-development evaluations of ICH tourism.

The second article is titled 'The effectiveness of marketing communication and importance of its evaluation in online environment', and is written by Krizanova et al. The article focuses on online marketing communication undertaken by hotels, and how to measure its effectiveness, which, according to authors, continues to be a challenge due to its complexity. Thus, in this article, the authors propose a methodology for implementing a suitable indicator for the evaluation of the effectiveness of online communication tools. They based their research on Slovakia's hotel industry, and on the current marketing communication activities hotels undertake by conducting a survey among the managers of Slovakian hotels. Their results suggest that hotels prefer financial metrics, because they represent a traditional approach towards investment evaluation. That is, return on investment (ROI) is the most common metric for assessing investments in online communication, and thus, the authors proposed ROI as the most-appropriate metric for evaluating the effectiveness of online marketing communication activities.

The third article, 'Measurement of satisfaction in sustainable tourism: a cultural heritage site in Spain' by Huete-Alcocer et al., analyzes sustainable tourism in a cultural context. The authors affirm that there are many factors that can influence the success of this type of tourism, but any action developed should be related to the satisfaction of the tourist. The work focuses on a heritage destination of an archaeological nature. The researchers studied the profile of the cultural tourist and his or her level of satisfaction after visiting the site. On one hand, the results show that tourists who visit heritage sites or archaeological parks seek a deeper cultural experience. Furthermore, they are well-informed and have planned their visit. On the other hand, they show that cultural tourism is based on a visitor profile that demands good infrastructure, informed guides, and clear information about the park or site, in addition to mid-level accommodation and catering services.

The fourth article also addresses an intangible cultural heritage, but in this case, in the south of Spain. The article is titled 'Flamenco tourism from the viewpoint of its protagonists: a sustainable vision using Lean Startup methodology', and was written by Millán Vázquez de la Torre et al. The authors explain the transition and evolution of flamenco from a form of popular music to an intangible cultural heritage of humanity. Using the Lean Canvas model combined with a survey of a panel of flamenco experts, the necessity to retain their place-based identity is pointed out, as well as the need, as a regional culture, to establish links to export markets for their survival, emphasizing the importance of high-quality communication and promotion, considering that the respect and maintenance of flamenco's essence are fundamental for the creation of a sustainable tourism product of quality in the medium and long terms. 
The fifth article, 'Perceived inconveniences and Muslim travelers' loyalty to non-Muslim destinations' by Han et al., identifies the process of generating loyalty for international Muslim travelers to non-Muslim destinations, taking into consideration the disadvantages these travelers may encounter when visiting a non-Muslim destination. Through qualitative interviews of Muslim travelers visiting South Korea and an analysis of the structural equation model, the results reveal that image, emotional experiences, and emotional desire play an important role in the loyalty of Muslim travelers. This research has several implications for non-Muslim destination management organizations (DMOs) aiming to attract and retain international Muslim travelers.

The sixth article is titled 'Exotic or home? Tourists' perception of guest houses, guest houses loyalty, and destination loyalty in remote tourist destinations', and was written by Shi et al. The article analyzes guest houses, a sustainable means of accommodation, and presents as a case study Kanas, a remote tourist destination in the autonomous region of Xinjiang, China. The conceptual model examines the cultural distance between residents and visitors in regard to the perceptions and loyalty of the guests. The results show that a large cultural distance increases the perception of an exotic culture and decreases the perception of a sense of home, as well as that both the perception of an exotic local culture and the sense of home have a positive effect on loyalty to the guest houses in this remote destination.

The seventh article, 'The development of loyalty to earthen defensive heritage as a key factor in sustainable preventive conservation' by Prados-Peña et al., examines whether the loyalty to a heritage site in Granada, Spain, emerges as a consequence of the perceived image visitors have of it and the level at which place attachment mediates the relationship between the effect of image and loyalty. Through a survey of 200 randomly selected respondents, the analyses confirm that the antecedent factors that determine loyalty are place attachment and its perceived image, which make it more likely that the site will be visited and recommended.

In the eighth article, 'The influence of Islamic religiosity on the perceived socio-cultural impact of sustainable tourism development in Pakistan: a Structural Equation Modeling approach', written by Aman et al., the authors analyze the influence of religion on the perception of the impact of the development of sustainable tourism based on the results of a survey of more than 500 residents of Pakistan. The findings show that respondents with a high level of Islamic religiosity have a positive attitude towards the development of sustainable tourism, as well as perceptions of communities, behaviors, and cultural aspects that affect sustainable tourism.

The ninth article of this special issue dedicated to sustainable tourism marketing is titled 'Tourism development, environment and policies: Differences between domestic and international tourists', and was written by Liu et al. The authors reveal that domestic and international visitors react differently to the air (environmental) quality of the destination. The authors used panel data (2005-2015) from 17 underdeveloped provinces in China, as well as an econometric model analysis, to explore the differences in the impact of air quality between domestic and international visitors, and how these differences may help local governments to establish tourism development policies.

The final article, 'The impact of disaster of a national airline on the nation's tourism: An empirical investigation' by Fan et al., addresses the issue of sustainable tourism marketing from a totally different perspective, analyzing the impact of an air disaster on travelers' attitudes and intentions to travel to a specific country. The authors apply authors apply this concept to Chinese tourists' intention to travel to Malaysia after the Malaysia Airlines disaster. To do so, they use a hybrid methodology using both quantitative and qualitative methods. The results show that intention to visit is positively affected by intention to fly on the specific airline and attitude toward visiting Malaysia. However, the effect of the perceived risk of flying this airline on attitudes about visiting the country is mediated by the perceived risk of visiting Malaysia and attitudes towards visiting it. The research concludes that knowledge about a country significantly reduces perceived risks about visiting it. Finally, public opinion reduces the perceived risk of using this airline. 
Author Contributions: All authors collaborated equally to this editorial. All authors have read and agree to the published version of the manuscript.

Funding: This research received no external funding.

Conflicts of Interest: The authors declare no conflict of interest.

\section{References}

1. Wu, T.-P.; Wu, H.-C.; Liu, S.-B.; Hsueh, S.-J. The relationship between international tourism activities and economic growth: Evidence from China's economy. Tour. Plan. Dev. 2018, 15, 365-381. [CrossRef]

2. Moral Moral, M.; Fernández Alles, M.T.; Sánchez Franco, M.J. Attitudes of rural accommodation managers towards the development of sustainable tourism. Cuad. Tur. 2018, 41, 707-711.

3. UNEP. Making Tourism More Sustainable: a Guide for Policy Makers; UNEP, UNWTO, Eds.; United Nations Environment Programme: Paris, France, 2005.

4. Sanagustín Fons, M.V.; Fierro, J.A.M.; y Patiño, M.G. Rural tourism: a sustainable alternative. Appl. Energy 2011, 88, 551-557. [CrossRef]

5. Jones, P.; Clarke-Hill, C.; Comfort, D.; Hillier, D. Marketing and sustainability. Mark. Intell. Plan. 2008, 26, $123-130$. [CrossRef]

6. Delmas, M.A.; Burbano, V.C. The drivers of greenwashing. Calif. Manag. Rev. 2011, 54, 64-87. [CrossRef]

7. Wu, Y.; Zhang, K.; Xie, J. Bad greenwashing, good greenwashing: Corporate social responsibility and information transparency. Manag. Sci. 2020. [CrossRef]

8. Hudson, S.; Fung So, K.K.; Li, J.; Meng, F.; Cárdenas, D. Persuading tourists to stay-Forever! a destination marketing perspective. J. Destin. Mark. Manag. 2019, 12,105-113. [CrossRef]

9. Font, X.; McCabe, S. Sustainability and marketing in tourism: Its contexts, paradoxes, approaches, challenges and potential. J. Sustain. Tour. 2017, 25, 869-883. [CrossRef] 